\title{
Evidence around engaging men in HIV prevention and treatment
}

\author{
Julie Pulerwitz \\ Population Council \\ Ann Gottert \\ Population Council \\ Jerry Okal \\ Population Council \\ Sanyukta Mathur \\ Population Council
}

Follow this and additional works at: https://knowledgecommons.popcouncil.org/departments_sbsr-hiv

Part of the Demography, Population, and Ecology Commons, Family, Life Course, and Society Commons, Gender and Sexuality Commons, and the International Public Health Commons How does access to this work benefit you? Let us know!

\section{Recommended Citation}

Pulerwitz, Julie, Ann Gottert, Jerry Okal, and Sanyukta Mathur. 2020. "Evidence around engaging men in HIV prevention and treatment," presentation at UNAIDS webinar, 15 April. 


\section{- POPUlation COUNCIL \\ Ideas. Evidence. Impact.}

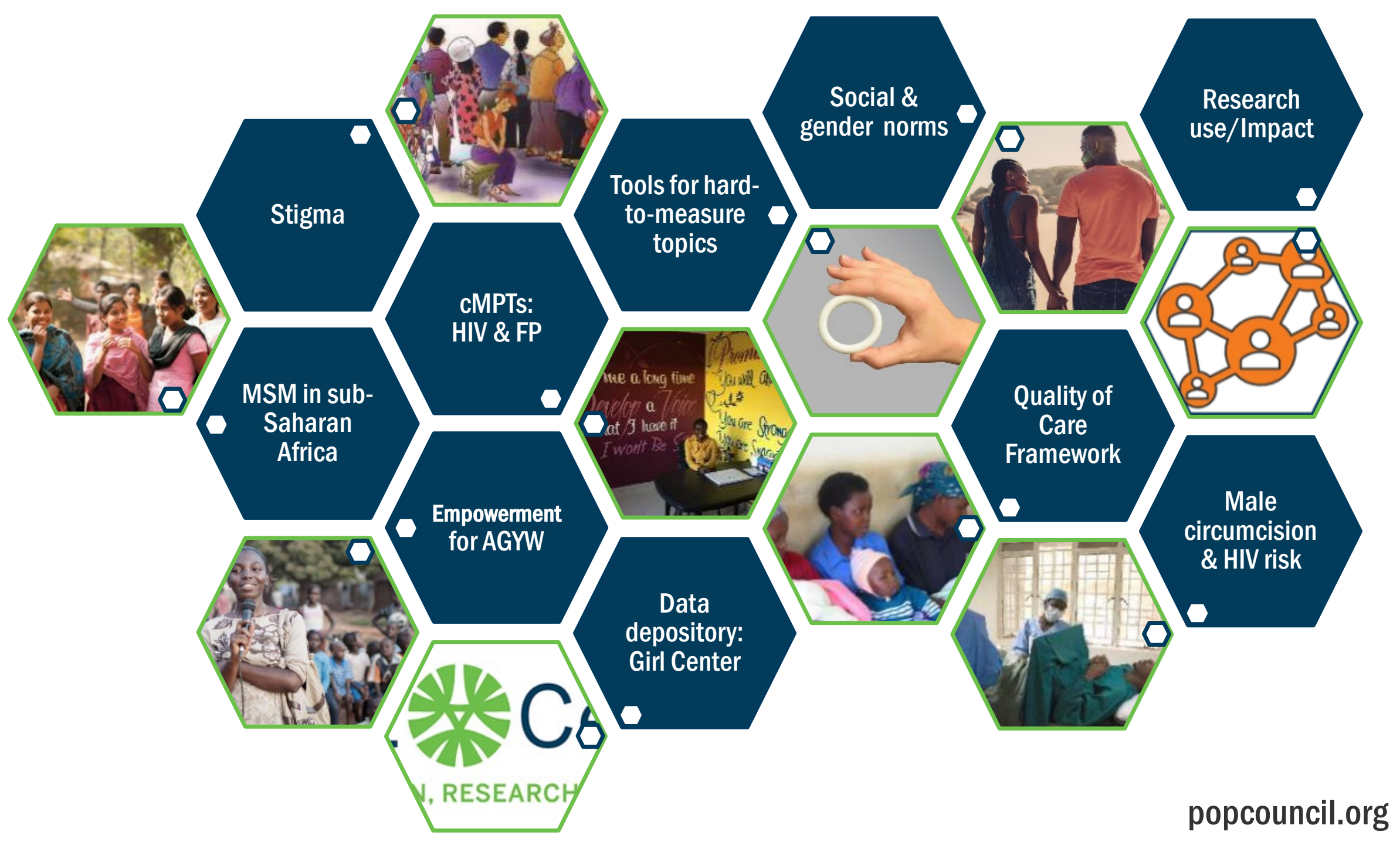




\section{Framing for today's presentation}

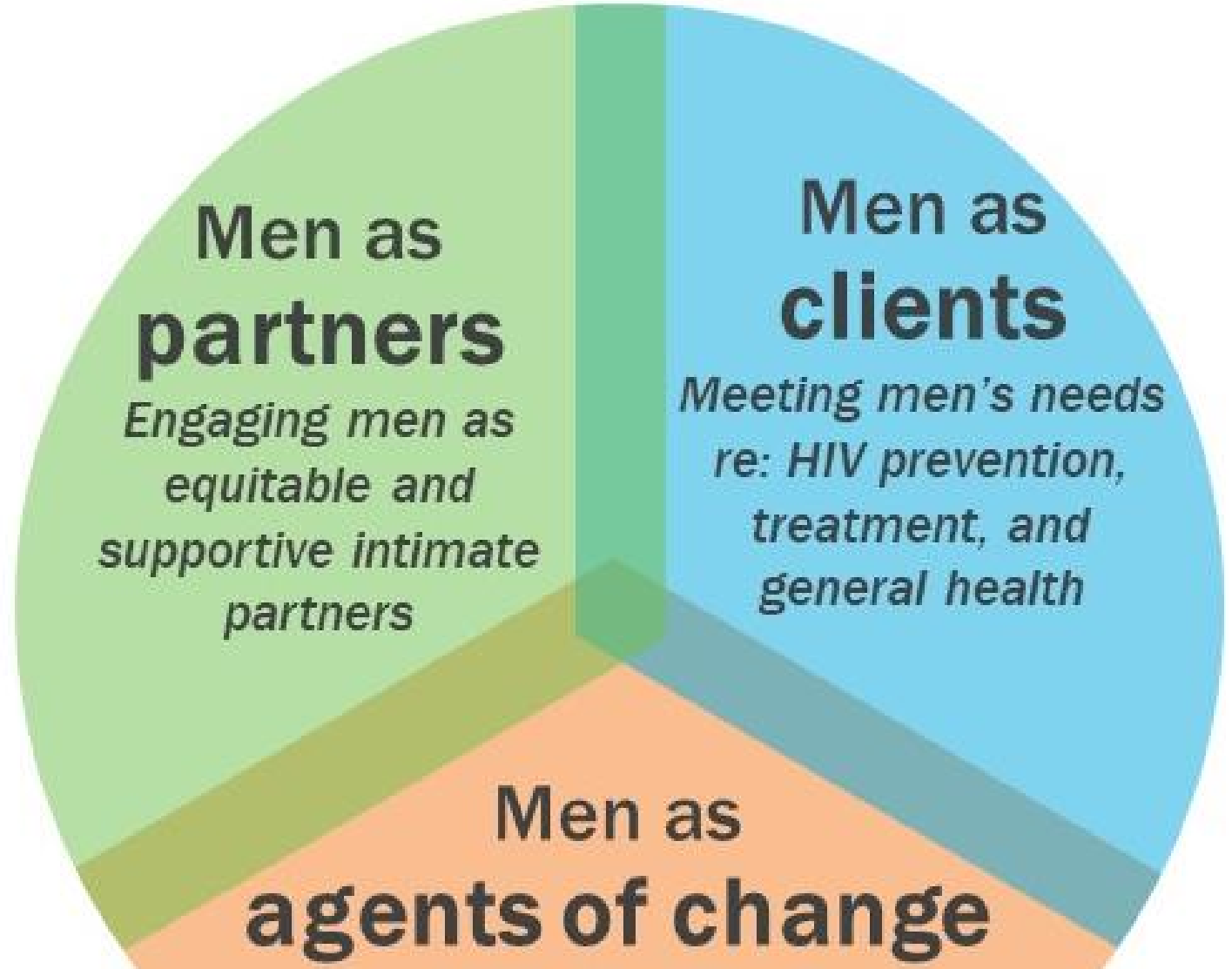

Engaging men in promoting HIV prevention and

gender equity 


\section{Settings of implementation research}




\section{Study designs/methods}

\begin{tabular}{|c|c|c|c|c|}
\hline & $\begin{array}{l}\text { Study } \\
\text { portfolio/ } \\
\text { funder }\end{array}$ & $\begin{array}{l}\text { Quantitative data with men } \\
\text { (cross-sectional surveys unless } \\
\text { otherwise noted) }\end{array}$ & $\begin{array}{l}\text { Qualitative } \\
\text { data with } \\
\text { men }\end{array}$ & $\begin{array}{c}\text { Program } \\
\text { implementing } \\
\text { partners }\end{array}$ \\
\hline $\begin{array}{l}\text { Eswatini } \\
(2017-18)\end{array}$ & DREAMS & $\begin{array}{l}\mathrm{n}=\mathbf{8 4 3} \text { (Round } 1 / \text { MEASURE } \\
\text { Evaluation survey) } \\
\mathrm{n}=1180 \text { (Round } 2 \text { ) }\end{array}$ & 66 IDIs & 3 FGDs \\
\hline Kenya & SOAR & n=124 facilities; $n=277$ clients & 32 IDIs & 8 IDIs \\
\hline $\begin{array}{l}\text { Malawi } \\
(2018-19)\end{array}$ & SOAR & $n=612$ & 4 FGDs & $A D D$ \\
\hline Nigeria & NIH & Cohort, $n=257$ MSM & - & - \\
\hline Nigeria & $\begin{array}{l}\text { Elton John } \\
\text { AIDS Fnd. }\end{array}$ & $\begin{array}{l}\text { Monitoring data from }>11,000 \\
\text { MSM }\end{array}$ & - & - \\
\hline $\begin{array}{l}\text { South Africa } \\
(K Z N) \\
(2017-18)\end{array}$ & DREAMS & $\begin{array}{l}n=962(\text { Round } 1) \\
n=886(\text { Round } 2)\end{array}$ & 72 IDIs & 3 FGDs \\
\hline $\begin{array}{l}\text { South Africa } \\
\text { (Mpumalanga) } \\
(2016-19)\end{array}$ & SOAR & $\begin{array}{l}n=1,149 \text { men \& women (Round 1) } \\
n=1,189 \text { men \& women (Round 2) }\end{array}$ & 59 IDIs & 39 IDIs \\
\hline $\begin{array}{l}\text { Uganda } \\
(2017-18)\end{array}$ & DREAMS & - & 126 IDIs & 9 FGDs \\
\hline
\end{tabular}




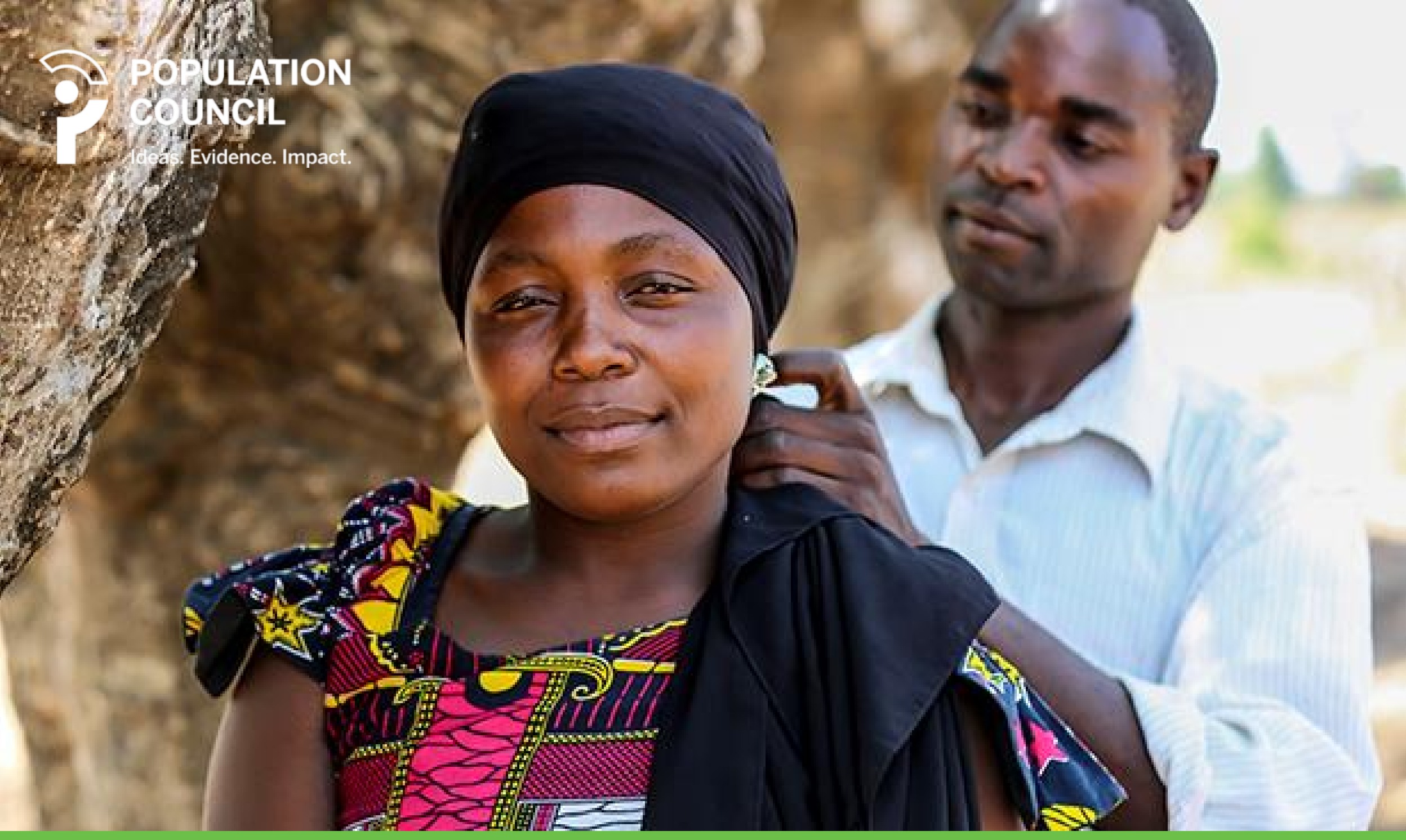

Engaging men as partners 


\section{Who are the men/male partners of adolescent girls and young women?}

- There are distinct subgroups/ profiles of men/male partners, who should be targeted differently with programming

- Not just older high-risk men, younger men have high HIV risk profiles too.

- Risk profiles of older and younger men don't look the same.

OLDER

HIGH

RISK

$23 \%$

of sample

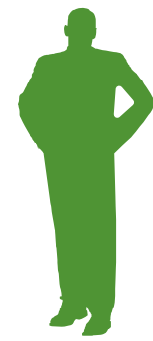

OLDER

LOW

RISK $25 \%$

of sample
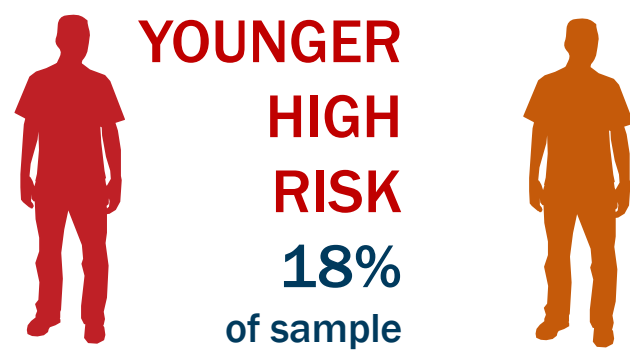

YOUNGER MODERATE

RISK $34 \%$

of sample

Study site: South Africa, $n=1,846$ (Similar groupings, with nuances, found in Eswatini) 


\section{Promising approach to creating HIV risk profiles}

- Latent class analysis (LCA) uncovers 'hidden' groupings in data

- Simultaneously combines multiple characteristics (e.g., demographics, attitudinal and behavioral)

- Builds on benefits of other quantitative and qualitative approaches

- Opportunity to develop complex picture using large sample

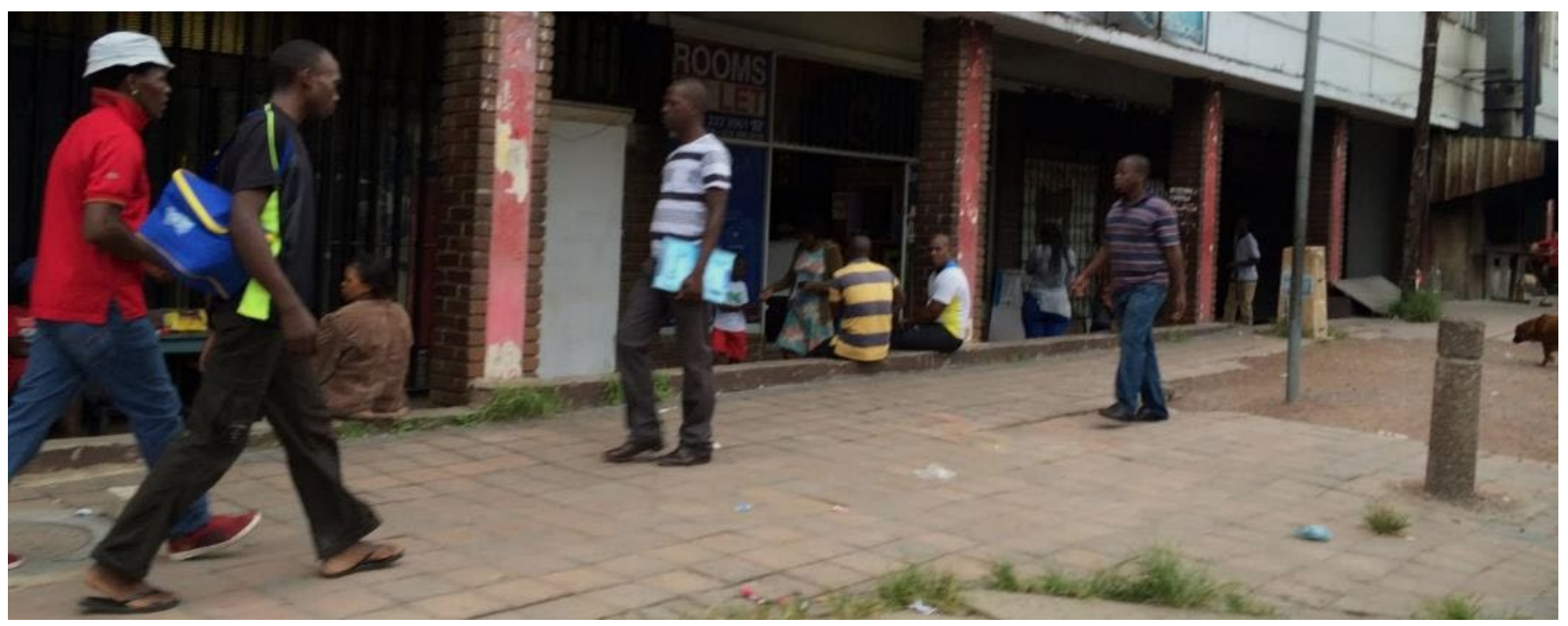




\section{What are the factors that distinguish HIV risk?}

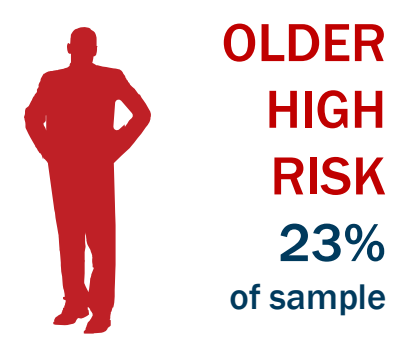

36 years old

Married/cohabiting

Informally/formally

employed

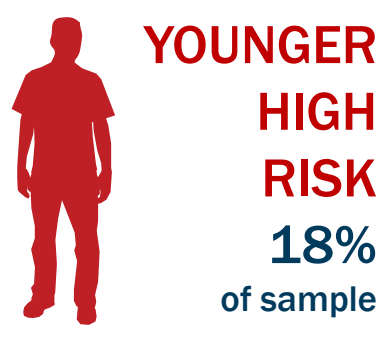

27 years old

Unmarried

Informally employed
31

\section{3 years old}

Unmarried

Unemployed, despite being university/ tech college grads

High \# of partners

Low age difference

Some transactional

relationships

Moderate alcohol abuse

Moderate gender inequity

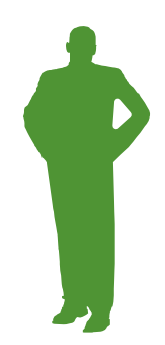

OLDER

LOW

RISK $25 \%$

of sample

29 years old

Married/cohabiting

Informally employed

Low \# of partners

Moderate age difference

Minimal transactional relationships

Moderate alcohol abuse

Low gender inequity

Moderate gender inequity

High gender inequity

relationships

High alcohol abuse

\author{
Moderate gender inequity
}

Low gender inequity 


\section{Gender attitudes a key distinguishing factor}

Highest-risk group = most gender-inequitable

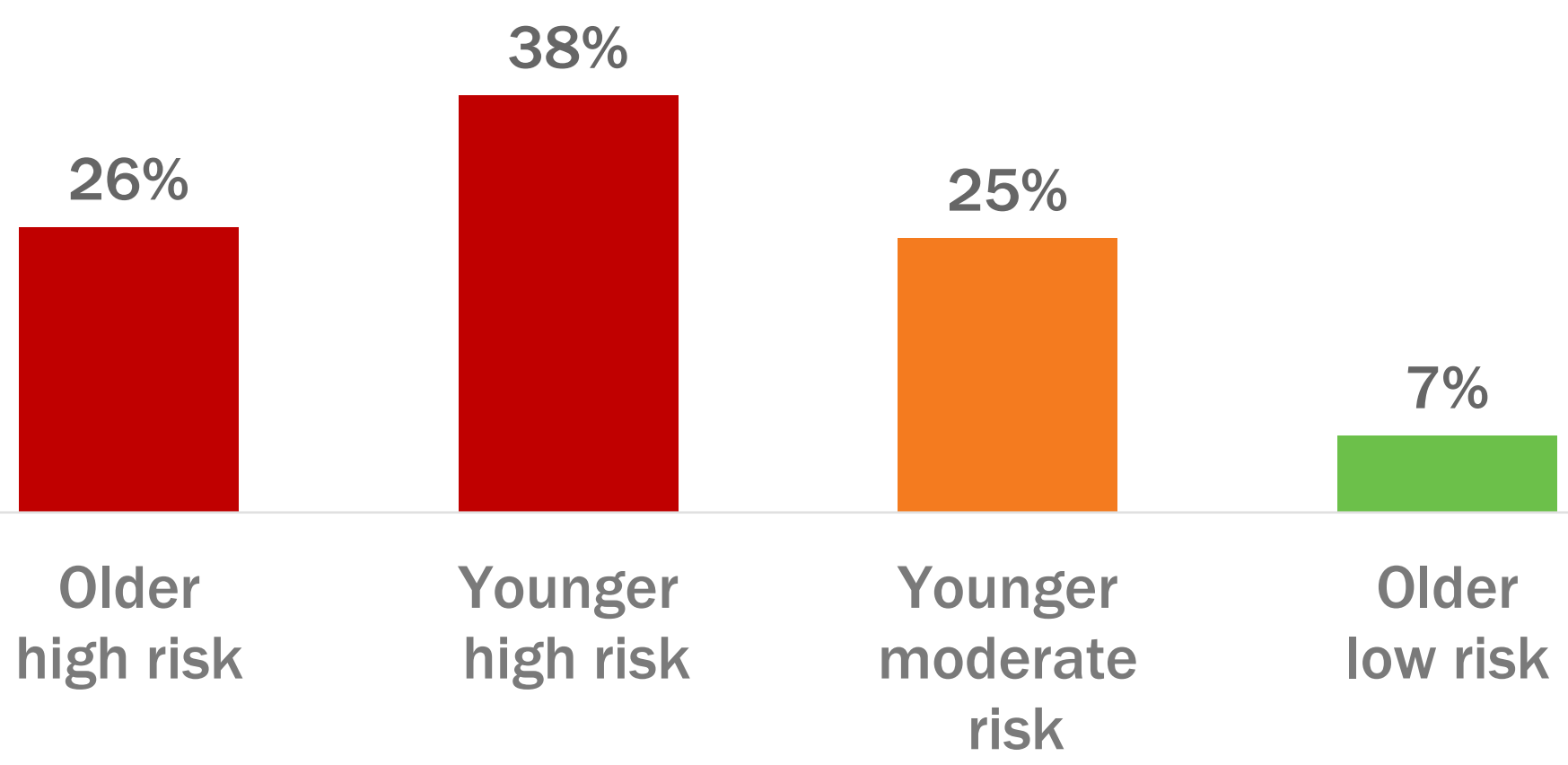

Endorsement of highly inequitable gender norms 


\section{What are men's relationships like?}

\section{Increasingly complex relationship patterns as men grow older}

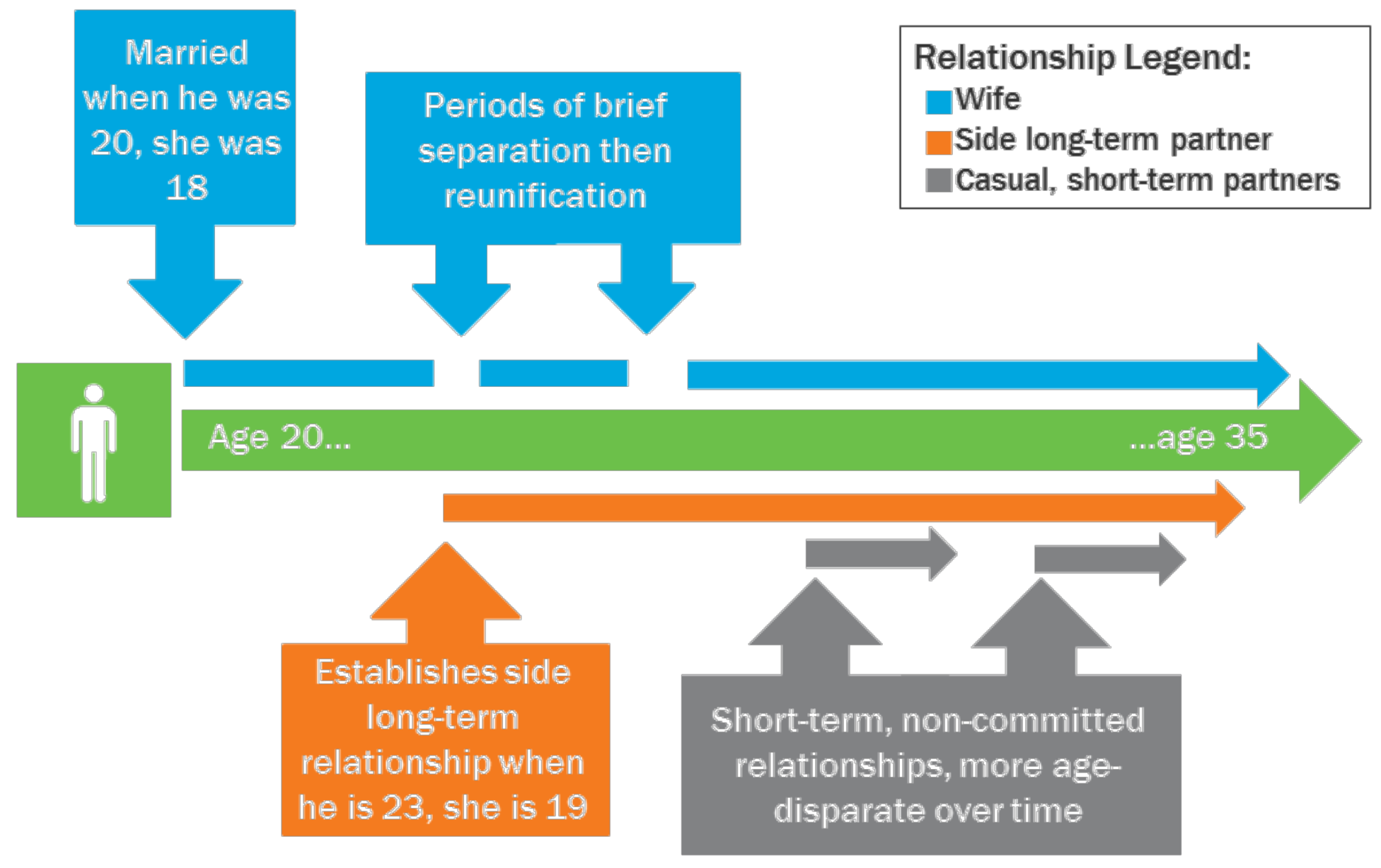

Study site: Uganda ( $n=94$ IDIs) 


\section{Relationships are dominated by conflict and miscommunication}

- Marital relationships filled with conflict-seen as inevitable and unresolvable

- Most relationships characterized by ineffective communication and distrust, resulting in delays in formalized partnerships and/or many side partners

...it is caused by lack of trust in relationships such that sticking to having one partner might cause issues such as if she cheats. So, it is very difficult to commit yourself to one individual; we end up having several partners.

-Man from Eswatini 


\section{Men think about their relationships in transactional terms}

- Men see money and gifts as the only way of establishing and maintaining relationships with women

- Men see most young women as active agents in pursuing transactional sex and mainly seeking material goods

- Many men intentionally seek young women because they are more compliant (i.e., power dynamics)

A man without money get a wife or sexual partner? It doesn't exist in our community.

-Man from Uganda

The young women listen and cooperate all the time, yet older women argue. 


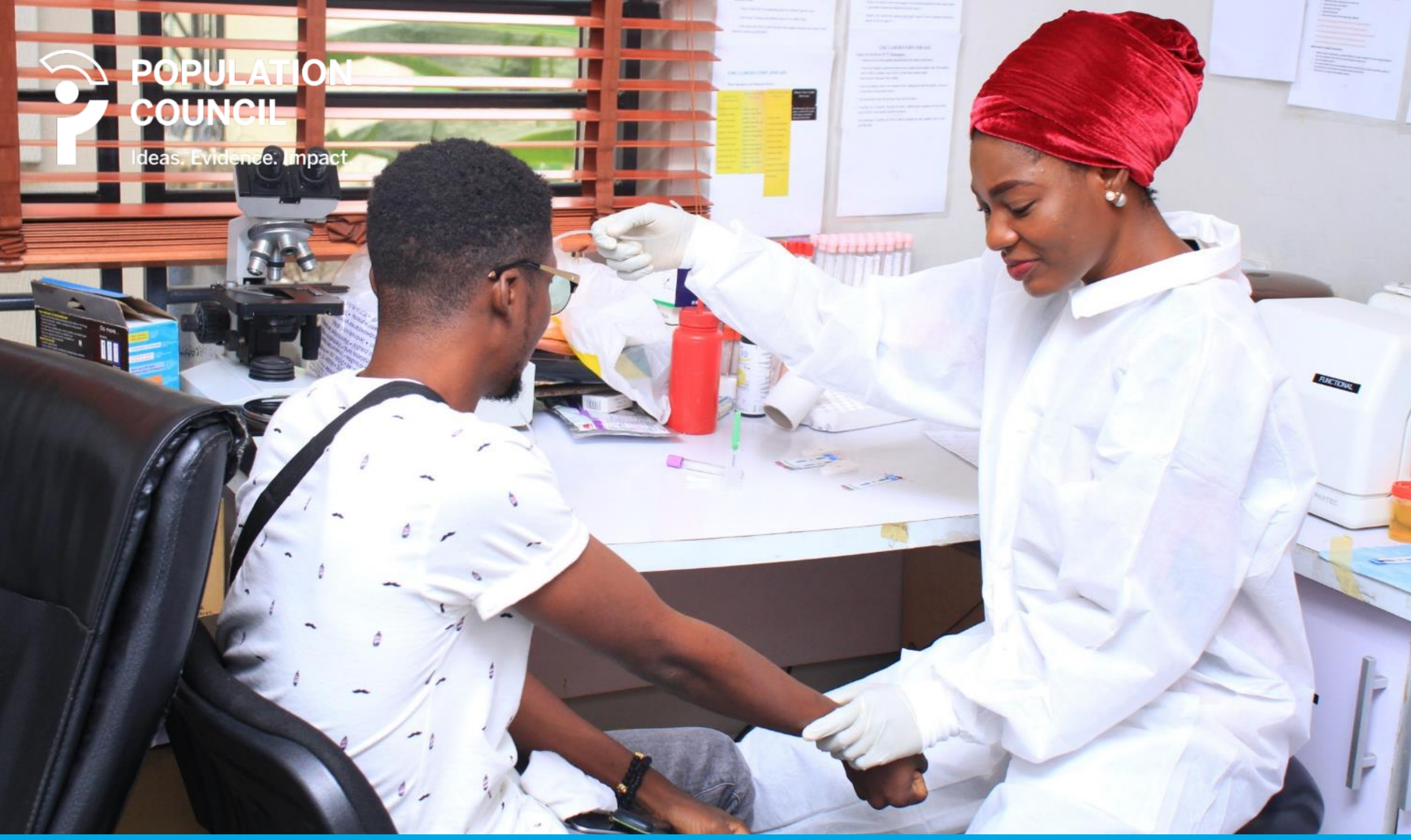

Engaging men as clients 
What are we learning about reaching men with HIV services?

Men in higher-risk profiles were less or no more likely to use
HIV services than lower-risk profiles

Tested for HIV

in last 12 months

Received VMMC

in last 5 years

\begin{tabular}{c|c|c|c|}
$\begin{array}{c}\text { Younger } \\
\text { mod. risk }\end{array}$ & $\begin{array}{c}\text { Younger } \\
\text { high risk }\end{array}$ & $\begin{array}{c}\text { Older } \\
\text { low risk }\end{array}$ & $\begin{array}{c}\text { Older high } \\
\text { risk }\end{array}$ \\
\hline
\end{tabular}

\begin{tabular}{|l|l|l|l|}
\hline $72 \%$ & $73 \%$ & $70 \%$ & $71 \%$ \\
\hline
\end{tabular}

${ }^{*} p<0.05|* * p<0.01| * * * p<0.001$

\begin{tabular}{|l|l|l|l}
\hline $52 \%^{* * *}$ & $36 \%$ & $21 \%$ & $14 \%$
\end{tabular}

Study site: South Africa, $n=1,846$ (Similar results in Eswatini) 


\section{Large gaps in men's HIV treatment knowledge}

\begin{tabular}{|lcc|}
\hline Believes that/knows about: & $\begin{array}{c}\text { South Africa } \\
(2017-2018) \\
n=1,847\end{array}$ & $\begin{array}{c}\text { Eswatini } \\
(2018) \\
n=1,099\end{array}$ \\
\hline Take treatment, stay healthy and live long & $94 \%$ & $75 \%$ \\
Good to take breaks from ART (false) & $22 \%$ & $14 \%$ \\
Treatment as prevention & $55 \%$ & $50 \%$ \\
Pre-exposure prophylaxis (PrEP) & $23 \%$ & $42 \%$ \\
\hline
\end{tabular}

Treatment literacy was not much better among men living with HIV in our studies in each country 


\section{Men's reactions to HIV testing vary}

- Willing yet non-proactive testers: most common

I didn't decide [to test], I met people like you doing door to door testing so I just used that chance and tested. (Age 31)

- Vigilant testers: perceived importance of early treatment

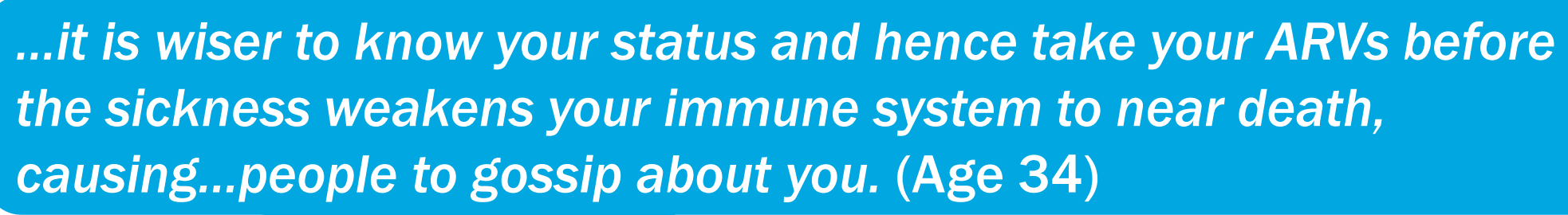

- Resistant testers: smallest group, yet also highest risk ...testing has to come from my heart before taking that decision....I don't want to take the decision yet in the end that thing will haunt me. ...I have never tested.... (Age 23) 


\section{What differentiates facilities with high vs. low volume of men coming for HIV testing?}

- Offer services 6 or 7 days/week (vs. 5)

- More likely to offer male key population services

- IDU (54\% vs. $27 \%, p<0.01)$

- MSM (60\% vs. 35\%, $p=0.01)$

- MSW (48\% vs. $28 \%, p=0.03)$

- Less likely to provide PMTCT services (57\% vs. $85 \%, p=0.001$ )

- No difference by public vs. private 


\section{What are men's testing experiences at facilities?}

- Most seeking HIV testing at facilities were repeattesters:

- 87\% had previously tested for HIV

- Typically test at facilities close to their home or workplace:

- Almost $40 \%$ tested at a facility because it was close to their home; 33\% because near their workplace.

- Some men are not receiving post-test counselling:

$-30 \%$ of repeat-testers were not counselled after last test

Study sites: Nairobi, Kenya ( $n=277$ men seeking HTS at public facilities) 


\section{Steps and time required to access HIV care}

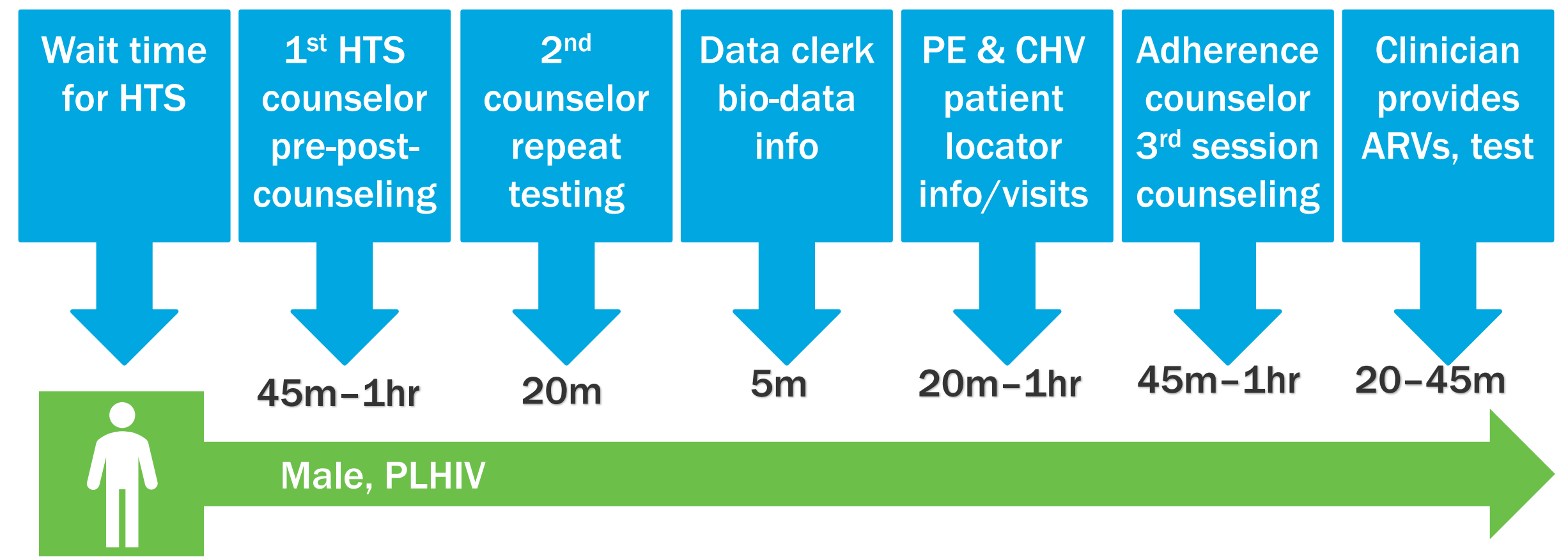

Study sites: Nairobi, Kenya ( $n=30$ IDIs with HIV positive men)

Okal, J., Lango, D., Matheka, J., Onyango, F., Ngunu, C. et al. "It is always better for a man to know his HIV status": A qualitative study exploring the context, barriers and facilitators of HIV testing among men in Nairobi, Kenya. PLOS ONE 2020, 15(4): e0231645. 


\section{What about key populations that may be harder to reach with services, such as MSM?}

- Peer educators (PEs) distributed oral HIV self-testing (HIVST) kits to their MSM networks

-320 recruited in 32 days by $12 \mathrm{PEs}$

- Oral HIVST is highly acceptable

- Most liked features:

- Easy to use

- Convenient

- Private and confidential

- 20\% had never tested for HIV

- $5 \%$ tested positive

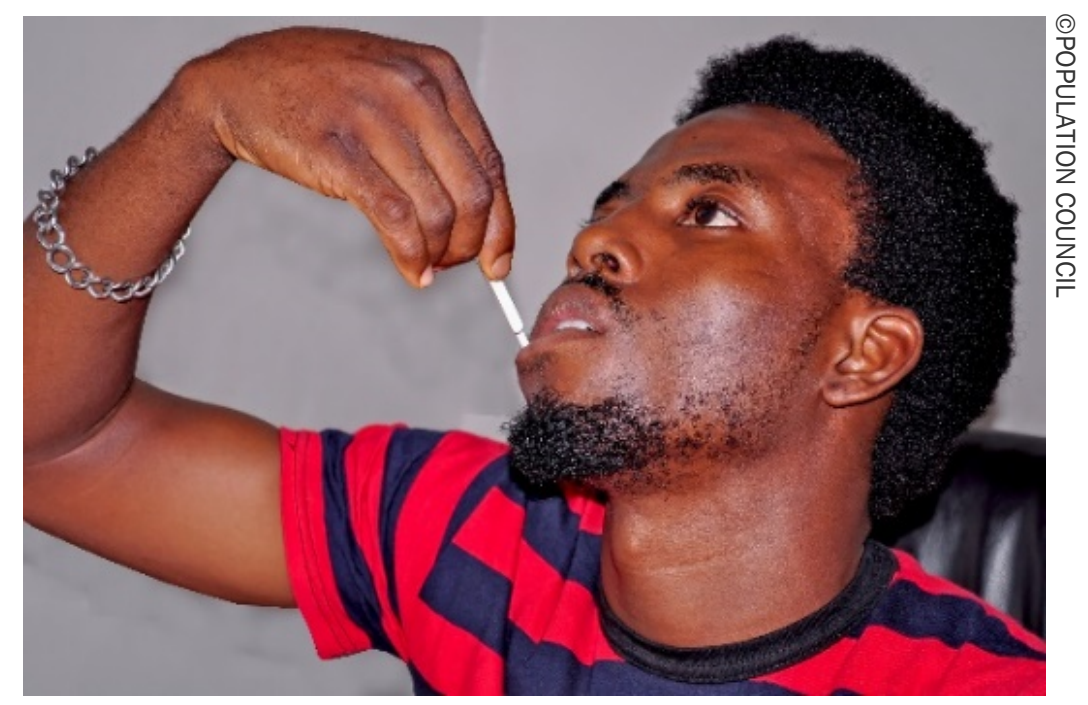

-All linked to treatment

Study site: Nigeria $(n=320)$

Tun. W., Vu, L., Dirisu, O., Sekoni, A., Shoyemi, E. et al. Uptake of HIV self-testing and linkage to treatment among 


\section{What are we learning about ART initiation and adherence?}

Agency and ownership over

own health
" When I finally came to and confirmed my status...they asked me whether they could start me on treatment. I said there is no negotiation over that; it is automatic that I start right away. I told them that is what brought me here. "(Uganda)
Supportive-yet-

directive

counseling from

providers
"It was clinic counselors during the 7-day classes [that helped me decide to start ART]. They give you genuine information during these classes, so that by the time you leave, you are able to separate facts from the stories, as far as HIV and ARV treatment goes. "(South Africa)
Informational \& instrumental social support
"[In] the support groups, we are able to encourage one another. So when you hear encouragement like this, you wonder, 'Can I stop taking the medication?' Then you tell yourself that, 'I must continue taking them. ' "(Malawi)

Still, few men knew if they had received viral load testing or if they were virally suppressed and few were aware of the effects of viral suppression on preventing transmission to their partners.

22 Study sites: Uganda, Eswatini, South Africa, Malawi $(n=92)$ 


\section{Hub and spoke model for improved access to HIV and support services}

- Peer navigation model for providing HIV treatment and psychosocial support services for MSM in Nigeria

- Hub: Population Council safe-space community health center

- 37 counselors/testers selected from MSM networks

- Spokes: 22 surrounding public health facilities

- 335 health care workers capacitated/sensitized to provide MSM-friendly services

- Community advisory committee: provided structural oversight and advocacy for project; critical in highly homophobic context

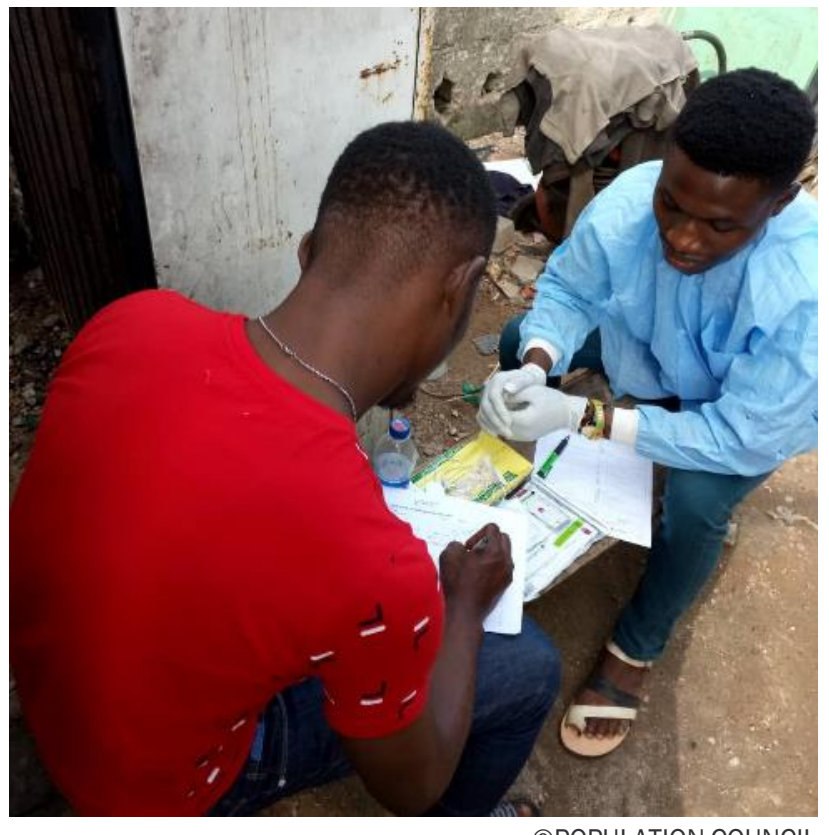

- Virtual social networking sites: increasingly a viable recruitment platform for hard-to-reach men

- Results: Between June 2016 and Dec 2018-11,276 MSM were reached with HTS, 971 (8.6\%) tested HIV positive, and 773 (80\%) were enrolled in treatment 


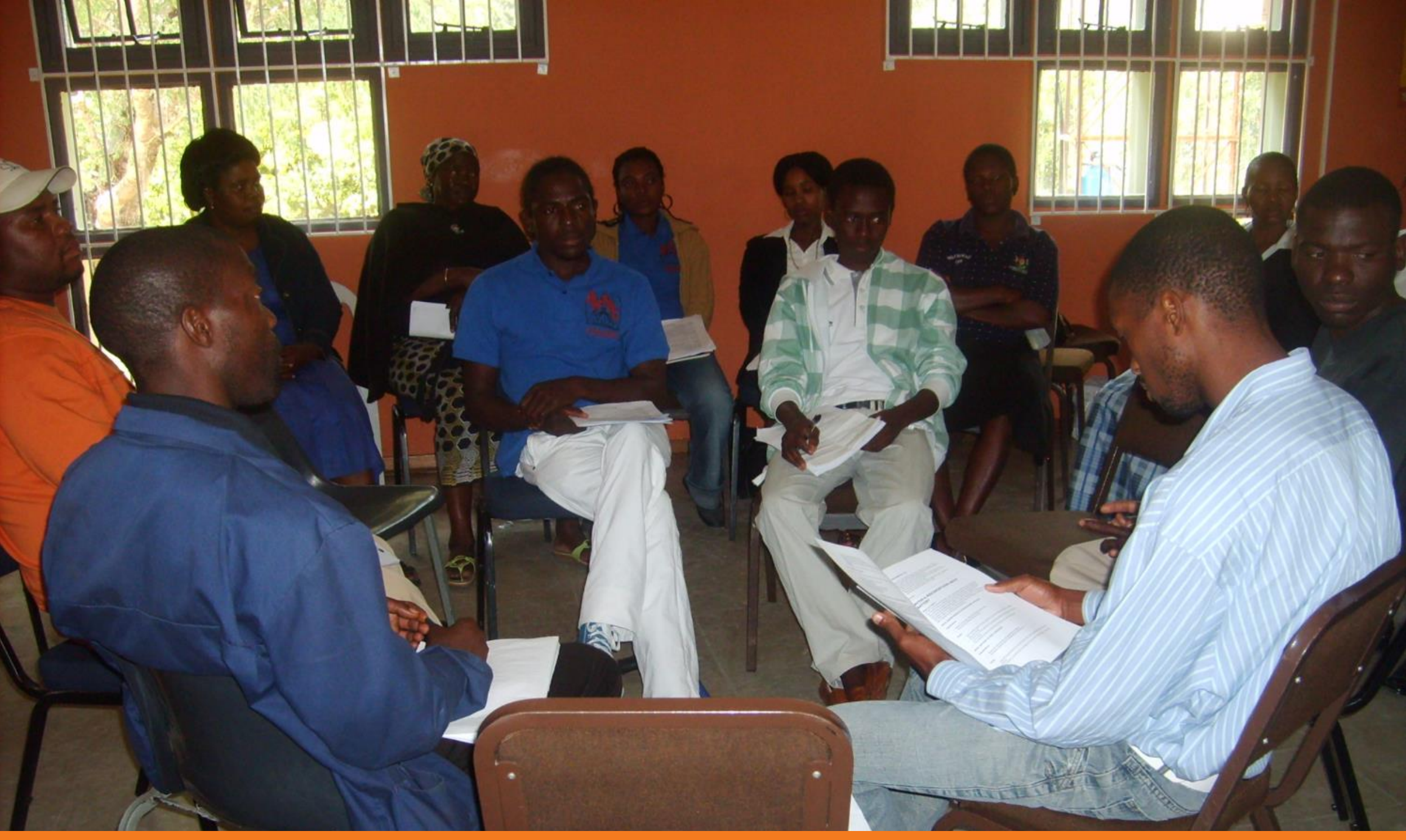

Engaging men as agents of change 


\section{Community-based gender transformational programming: promising strategy}

- Tsima "Working together"-3 year community mobilization intervention (2015-18) in rural Mpumalanga, South Africa

- Main focus: Improving uptake of HIV services

- Strong focus on engaging men (and women) as agents of change

- Regular mixed sex workshops included critical reflection and taking action around health, gender equity, human rights, and stigma

- Explicit messages to shift gender norms that inhibit HIV service use and justify sexual and gender-based violence

- Village leadership publicly supported activities

- Community Action Teams/program staff assigned to each village-both men and women

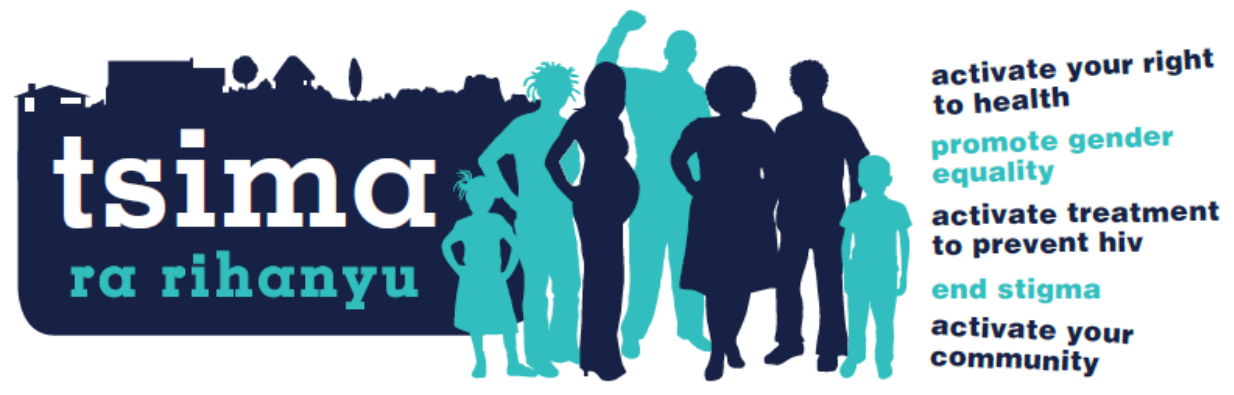




\section{Baseline demonstrated importance of shifting gender norms for both men and women}

- Endorsement of inequitable gender norms associated with lower odds of treatment (ART) use

\begin{tabular}{|lcc|}
\hline & HIV-positive & HIV-positive \\
& WOMEN & MEN \\
& $(n=122)$ & $(n=48)$ \\
GEM Scale (mean score, 23 items) & aOR & a. \\
Higher=more inequitable & $0.2 * *$ & 0.6 \\
Men's violence and control over women & $(0.1,0.5)$ & $(0.1,3.8)$ \\
Men as decision-maker in a couple & $0.3 *$ & 1.1 \\
& $(0.1,1.0)$ & $(0.2,5.4)$ \\
Men's toughness and avoidance of help-seeking & $0.2 * *$ & $0.3 *$ \\
& $(0.1,0.5)$ & $(0.1,0.9)$ \\
& $0.4 *$ & 0.8 \\
\hline
\end{tabular}

${ }^{*} p<0.05 * * p<0.01 * * * p<0.001$; Controlling for age, marital status, education 


\section{Population-level shifts in gender norms are possible}

- Cluster randomized controlled trial of Tsima showed large increases in equitable gender norms in both intervention and control communities

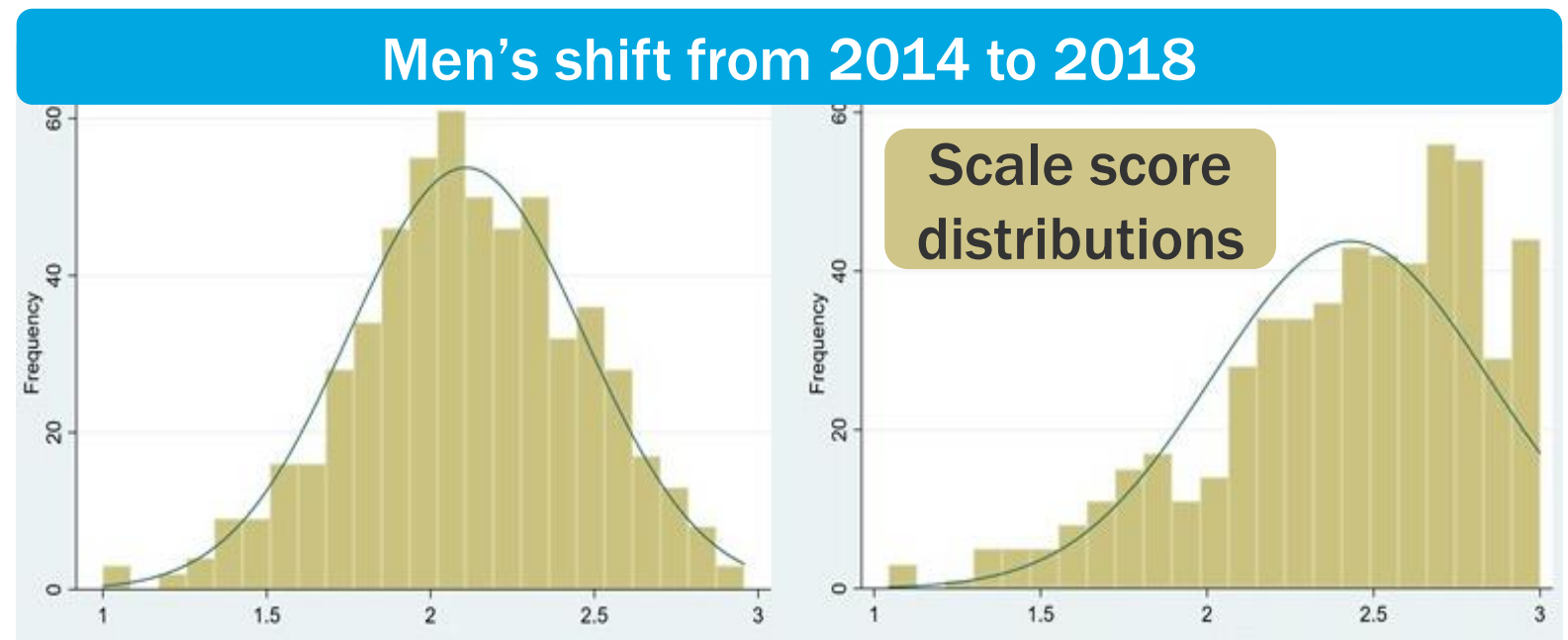

Qualitative research suggested shifts were influenced by recent, rapid increase in access to media (satellite TV, smartphones) 


\section{Intervention led to decreases in partner violence}

- Among women ages 18-29, the intervention was associated with half the odds of IPV

- Adj. Odds Ratio $0.48(p<0.05)$

- Qualitative findings:

- Reduced IPV in intervention villages was attributed to couples learning to communicate more constructively through Tsima

- Broader shifts in norms may have been critical enabler of reduced IPV

I was not communicating with her...She was always complaining about it, arguing and sometimes I was abusing her physically when she complained, but Tsima has changed that, we always communicate nowadays.

-Male community member 


\section{More equitable and constructive couple communication also facilitated HIV service uptake}

I will give you an example about a man who attended support groups... He told us that his wife did not trust him and there was no communication with her... Tsima helped him. He disclosed his status to his wife and children, and they remind him to take his treatment.

Note: Analyses are still underway regarding effect of Tsima on primary trial outcomes of HIV testing and treatment uptake 


\section{New resource that sums up today's findings}

- Developed by the Male Engagement Task Force of USAID Interagency Gender Working Group (IGWG)

- Intended for programmatic and policy audiences

- Brief 2-pager

- Applicable across health areas

$-\mathrm{RH}, \mathrm{HIV}, \mathrm{MCH}$ (and others, e.g., GBV)

- Represents lessons learned over time

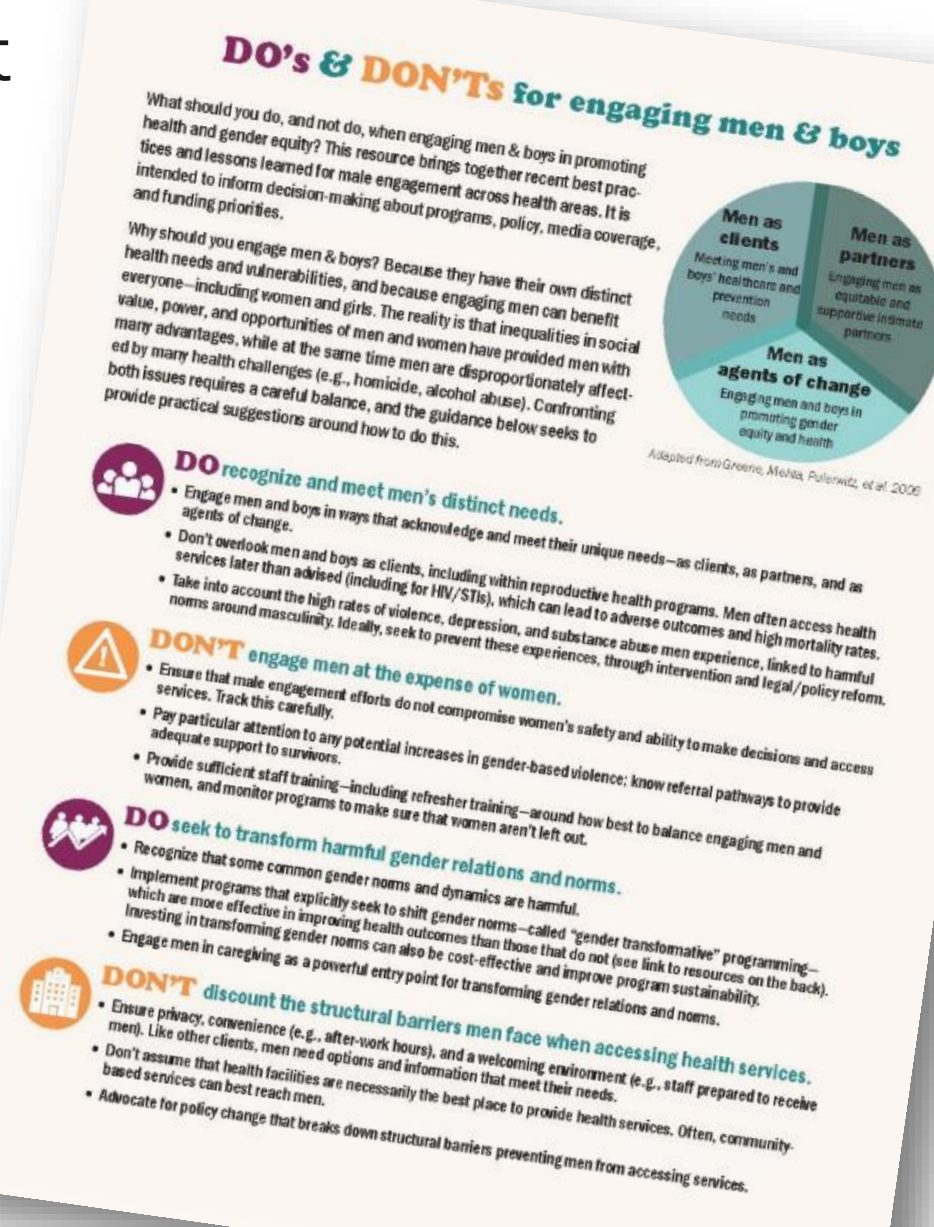


(39)

DO recognize and meet men's distinct needs.

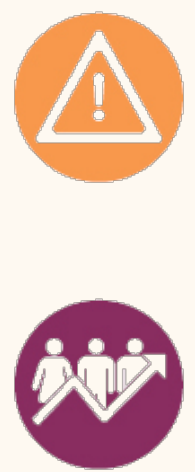

DON'T engage men at the expense of women.

DO seek to transform harmful gender relations and norms.

DON'T discount the structural barriers men face when accessing health services.

(17) DO gather evidence with men and boys (and not just women and girls).
DON'T start with the assumption that all men are bad actors.

DO start early in the life course.

DON'T overlook the diversity of men and boys in the population.

DO engage men on their own and in groups of men, as well as together with women.

DON'T overlook scale and sustainability for achieving impact. 


\section{COVID-19 commentary under development}

\section{"Men and COVID-19: Where should our focus be?"}

- Key suggestions for COVID-19 response:

- Address barriers to men's timely engagement in care (particularly critical for COVID-19), that are deeply rooted in gender norms and beliefs

- Use available tools to promote healthy communication and mitigate conflict among couples/families during stay-at-home orders

- Build in research on the gendered effects of COVID-19, including disproportionate mortality among men, taking race/ethnicity, age, and other factors into account

- Authors (from Male Engagement Task Force): Myra Betron, Ann Gottert, Julie Pulerwitz, Dominick Shattuck, Natacha Stevanovic-Fenn 


\section{Acknowledgements}

DREAMS Male Partner Studies

Population Council: Ann Gottert, Julie Pulerwitz, Sanyukta Mathur, Louis Apicella, Jerry Okal, Craig Heck, Nrupa Jani, John Mark Wiginton, Cristian Valenzuela, Pamela Keilig, Ellen Weiss, Sherry Hutchinson

\section{South Africa}

Local research partner-Epicentre: Cherie Cawood, Elsa Marshall, David Khanyile, Dominique O'Donnell, Research assistants. In collaboration with: South African DOH, SANAC, eThekwini Municipality, PEPFARSouth Africa, DREAMS implementing partners

\section{Eswatini}

Local research partner-Institute for Health Measurement (IHM): Patrick Shabangu, Kelvin Sikwibele, Bhekumusa Lukhele, Feziwe Makhubu, Vimbai Tsododo, Bheki Mamba, Research assistants; Muhle Dlamini (SNAP); Muziwethu Nkhambule (NERCHA).

In collaboration with: Ministry of Health, NERCHA, SNAP, PEPFAR-Eswatini, DREAMS implementing partners

\section{Uganda}

Local research partner-Makerere University, Child Health and Development Centre (CHDC): Godfrey Siu, Anne Katahoire, Florence Ayebare, Research assistants. In collaboration with: Ministry of Health, District local government, PEPFAR-Uganda, DREAMS implementing partners

\section{With funding support from the Bill \& Melinda Gates} Foundation

\section{Project SOAR}

\section{Malawi DREAMS}

Population Council: Sanyukta Mathur, Nanlesta Pilgrim, Lyson Tenthani, Tracy McClair, Nrupa Jani, Kasoda Kondwani

University of Malawi, College of Medicine: Effie Chipeta, Wanangwa Chimwaza, Vincent Samuel, Victor Mwapasa

\section{South Africa Gender Norms}

Population Council: Ann Gottert, Nicole Haberland, Julie Pulerwitz

Wits/MRC-Agincourt Unit: Lumbwe Chola, F. Xavier Gómez-Olive, Chodziwadziwa Kabudula, Kathleen Kahn, Nkosinathi Masilela, Stephen Tollman, Rhian

Twine, Ryan Wagner

Wits/MRC-Agincourt Unit and University of North

Carolina: Aimée Julien, Audrey Pettifor

Wits/MRC-Agincourt Unit and University of California, San Francisco: Sheri Lippman

University of California, San Francisco: Mi-Suk KangDufour, Anna Leddy, Rebecca West

Sonke Gender Justice: Rhandzekile Mathebula, Dean Peacock, Dumisani Rebombo

Right to Care: Ian Sanne

Kenya HTS

Population Council: Jerry Okal, Avina Sarna, James Matheka, Daniel Mwanga, Roopal Jyoti Singh

Ministry of Health (NASCOP): Mary Mugambi Nairobi City County Government: Carol Ngunu-Gituathi, Moses Owino

Nairobi County Health Centers Staff

All SOAR studies: Study participants

With funding support from PEPFAR and USAID
Nigeria

\section{HIVST among MSM}

Population Council: Waimar Tun, Lung Vu, Osasuyi Dirisu, Adekemi Sekoni, Liz Shoyemi, Jean Njab, Sade Ogunsola, Sylvia Adebajo

\section{With funding support from U.S. National Institutes of} Health

Strengthening integrated delivery and access Population Council: Osasuyi Dirisu, Sylvia Adebajo, George Eluwa, Waimar Tun, Jean Njab, Michael Kunnuji

With funding support from Elton John AIDS Foundation
POPULATION COUNCIL 


\section{Ideas. Evidence. Impact.}

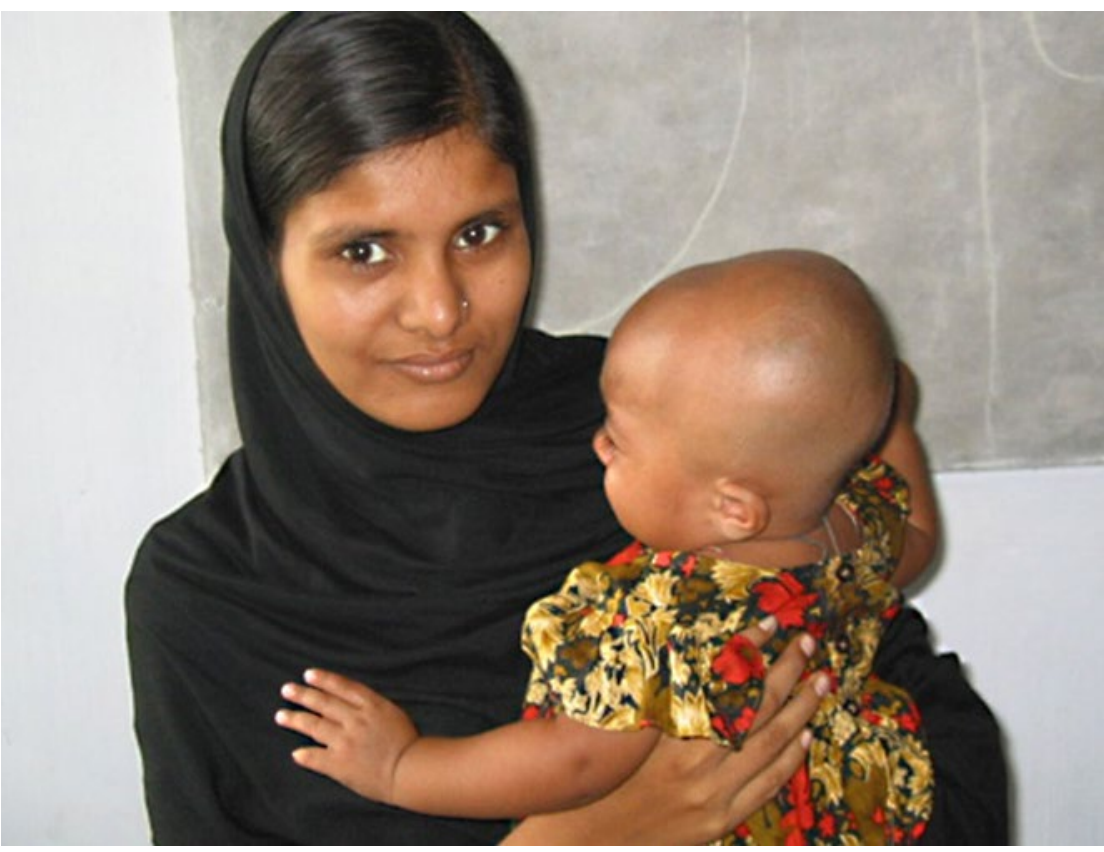

The Population Council conducts research and delivers solutions that improve lives around the world. Big ideas supported by evidence: It's our model for global change.

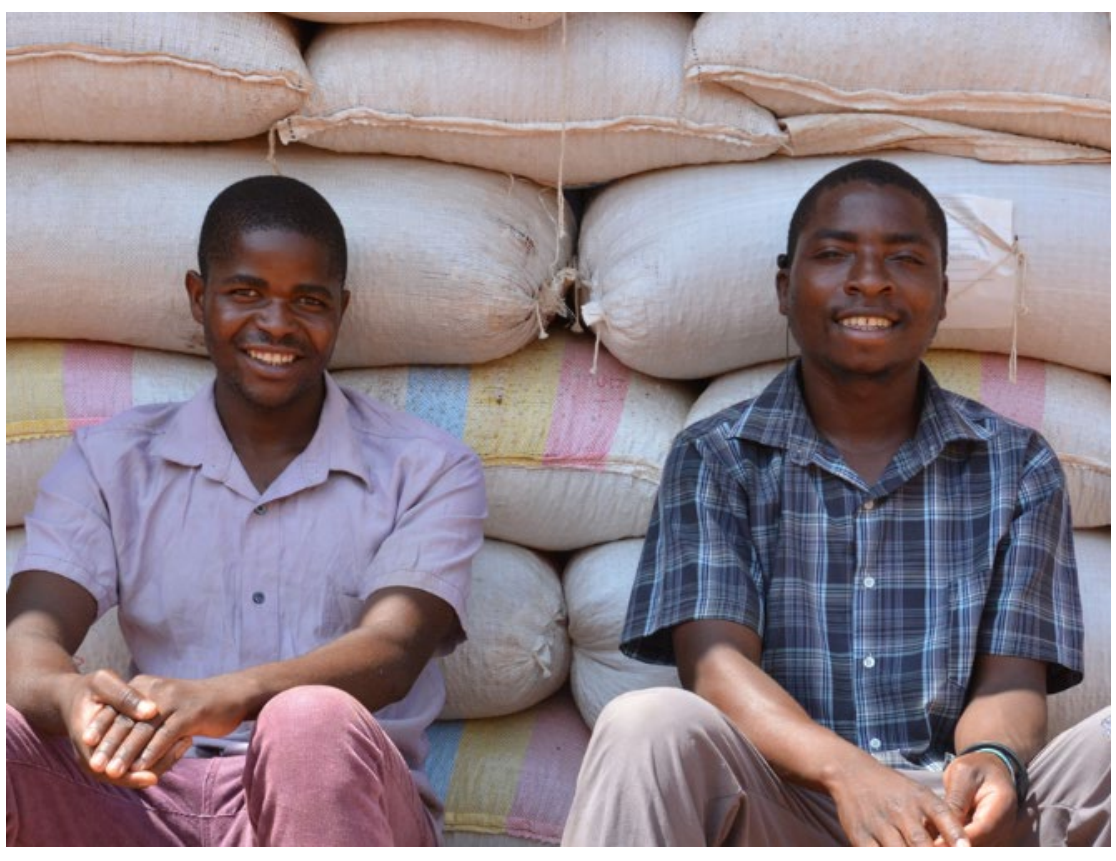

(2) popcouncil.org

凶jpulerwitz, jokal, smathur, agottert (@popcouncil.org)

(9Pop_Council, @Pulerwitz, @okalj, @SanyuktaMathur 


\section{POPULATION}

\section{COUNCIL}

Ideas. Evidence. Impact.

(C) 2020 The Population Council. All rights reserved.

Use of these materials is permitted only for noncommercial purposes. The following full source citation must be included:

Population Council. 2020. "Evidence around engaging men in HIV prevention and treatment." Presented at UNAIDS and Population Council Men and Boys Engagement webinar, 15 April.

This presentation may contain materials owned by others. User is responsible for obtaining permissions for use from third parties as needed. 